\title{
Calculando la vejez: gestión previsional en trabajadores/as de bajos ingresos ${ }^{1}$
}

\author{
Aldo Madariaga E.* \\ Nicolás Pérez $\mathrm{M}^{* * 2}$
}

\begin{abstract}
Resumen
El sistema de pensiones chileno constituye un hito en cuanto a la institucionalización de la responsabilidad individual y las decisiones individuales como determinante del desempeño previsional. Pocas evaluaciones se han realizado, sin embargo, a la manera como las personas toman sus decisiones en este sistema. A partir de un estudio cualitativo, el siguiente artículo explora cómo trabajadores/as de bajos ingresos de la ciudad de Santiago toman sus decisiones previsionales. Utilizando perspectivas recientes dentro de la sociología económica, el artículo ofrece una interpretación dinámica de las posibilidades de agencia en un escenario social complejo y novedoso, con foco en la construcción de marcos de calculabilidad que permiten tomar decisiones, y los elementos estructurales e institucionales que los condicionan. Estos últimos desbordan los marcos construidos y hacen necesarios procesos de re-encuadre por medio de los cuales la gestión previsional se entremezcla con estrategias para la generación de ingresos actuales.
\end{abstract}

Palabras clave: Sistema de pensiones - encuadre - gestión previsional - desbordamiento - marcos de calculabilidad.

\begin{abstract}
The Chilean pension system is a milestone regarding the institutionalization of individual responsibility and individual decisions as determinant of the pension performance. Few assessments have been made, however, to how people make decisions in this system. From a qualitative study, the following article explores how low-income workers living in Santiago make their pension decisions. Using recent perspectives in economic sociology, the article provides a dynamic interpretation of the possibilities of social agency in a complex and novel scenario, focusing on the construction of calculability frameworks that permit to make decisions and the structural and institutional elements that condition them. The last ones overflow the constructed frameworks and make necessary reframing processes through which the pension management intermingles with strategies for the generation of current incomes.
\end{abstract}

Keywords: Pension system - framing - pension management - overflowing - calculability frameworks.

1 Este material está basado en la investigación apoyada por The Regents of the University of California, Institute for Money, Technology \& Financial Inclusion. Cualquier opinión, hallazgos y conclusiones o recomendaciones expresadas en esta publicación corresponden al(los) autor(es) y no necesariamente representan el punto de vista de esta institución.

* Sociólogo, Universidad de Chile. MA en Ciencia Política/Economía Política, Central European University. Investigador Doctoral del Max Planck Institute for the Study of Societies.

** Licenciado en Sociología, Universidad de Chile.

2 Los autores agradecen al equipo que participó en la investigación y a Catalina Arteaga, Rodrigo Figueroa, Bill Maurer, José Ossandón, María Luisa Marinho y los revisores anónimos de esta revista quienes colaboraron con valiosos comentarios y sugerencias a este artículo. Fabiola Rivera constituyó una ayuda vital durante todo el proyecto, tanto en lo formal como en lo sustantivo. Errores u omisiones son de absoluta responsabilidad de los autores. 


\section{INTRODUCCIÓN}

El sistema de pensiones chileno, de ahorro en cuentas individuales administradas por instituciones privadas (AFP), constituye todo un hito en materia de política pública. Tanto la reforma de 1980 que institucionalizó los mecanismos de mercado como puntales de la seguridad social en el país, como la reciente reforma de 2008 que devolvió al Estado un cierto rol en la mitigación de los efectos del mercado, han sido catalogadas como ejemplos de política pública y han recibido amplia atención y difusión internacional (Mesa-Lago, 2008; Arenas de Mesa, 2010).

Uno de los supuestos con que trabaja el sistema es que las pensiones debieran reflejar estrechamente las decisiones que los actores realizan en parámetros clave a lo largo de sus vidas laborales (Berstein y Cabrita, 2006: 30), hecho por el cual el estudio de la toma de decisiones en el sistema de pensiones resulta fundamental (cf. Madariaga y Pérez, 2009). Llama la atención, sin embargo, la falta de dichas investigaciones, especialmente en contraste con el caudal de estudios realizados a otros aspectos del sistema ${ }^{3}$.

Los estudios económicos dedicados a la toma de decisiones en materia previsional en Chile y otros países se han concentrado en fenómenos como la incidencia de las fallas de mercado (especialmente la cantidad y calidad de la información) en las decisiones previsionales (Chan y Stevens, 2003), por ejemplo aquellas relacionadas con la elección y cambio de administradora (Sundén, 2005; Berstein y Ruiz, 2005; Berstein y Cabrita, 2006), la decisión de jubilar anticipadamente (Ruiz-Tagle y Tapia, 2011) y las dificultados que enfrentan los agentes al procesar información numerosa y compleja (Loewenstein, 1999; Cronqvist y Thaler, 2004). Aun cuando la mayoría de ellos se basan en extensiones de la teoría microeconómica neoclásica, como la economía del comportamiento [behavioural economics] que ha dedicado esfuerzos importantes en incorporar a sus modelos las limitaciones cognitivas de los agentes económicos (véanse Camerer y Loewenstein, 2004), los efectos de los factores sociales, culturales y políticos que pesan sobre dichos procesos son sistemáticamente dejados de lado (Granovetter, 1985; Zukin y DiMaggio, 1990; Bourdieu, 2001). Comprender la toma de decisiones en escenarios altamente complejos y alejados de la vida cotidiana como el sistema de pensiones chileno sin considerar estos elementos resulta particularmente desafiante en el caso de trabajadores/as de bajos ingresos cuya capacidad de elegir, más allá de la falta de información, se ve obstaculizada por severos condicionantes estructurales e institucionales (baja educación, altas tasas de rotación laboral e informalidad) y normativos (escasez de marcos de acción o experiencias previas significativas para gestionar decisiones financieras sobre la vejez).

3 Por ejemplo, aquellos referidos a la relación entre el sistema de pensiones y el crecimiento económico (Corbo y Schmidt-Hebbel, 2003; Uthoff, 2001), proyecciones del desempeño basadas en la relación de las personas con el mercado del trabajo (Arenas de Mesa, 2006; Berstein et al., 2005; CENDA, 2005), incluidas las diferencias de género (Cox, 2000), las fallas del mercado de administradoras (Arrau y Valdés, 2002; Valdés, 2005), entre otros. 
El presente artículo presenta una interpretación sociológica de los procesos de toma de decisiones en el sistema de pensiones chileno utilizando datos de un estudio cualitativo llevado a cabo por los autores ${ }^{4}$. Esta se fundamenta en teorías pragmáticas de la acción (Joas y Beckert, 2001; Beckert, 2003) que permiten conceptualizar la relación entre rutina e innovación de manera dinámica, incorporando además una reflexión más amplia respecto de la construcción de mercados y de agentes capaces de tomar decisiones en éstos, o lo que Çalışkan y Callon (2010) denominan procesos de economización (Callon, 1998b; Callon y Muniesa, 2005). La aplicación de estos enfoques ha permitido mejorar la comprensión de cómo es posible el diseño de mercados-como-política-pública (Ossandón, 2009; Ossandón y Ureta, 2012), la generación de marcos de referencia que permiten cálculos financieros aún en contextos de alta vulnerabilidad (Villarreal, 2011), y la manera en que ámbitos de acción previamente desconocidos como aquel provisto por las tarjetas de crédito en personas con bajos niveles de bancarización son aprehendidos e incorporados a las prácticas cotidianas (Barros, 2012). A su vez, descansa en los hallazgos de investigaciones cualitativas provenientes de la antropología social y la sociología que han intentado conceptualizar las estrategias de individuos y familias latinoamericanos de bajos ingresos frente a decisiones económicas complejas -por ejemplo, el enfrentamiento de la pérdida de trabajo o de una crisis económica-combinando la posibilidad de agencia con la existencia de condicionantes estructurales e institucionales (Kaztman y Filgueira, 1999; Kaztman y Wormald, 2002; González de la Rocha, 2006).

El texto argumenta que las decisiones que los trabajadores/as de bajos ingresos toman respecto de su previsión son posibles gracias a la construcción de marcos para la acción -O marcos de calculabilidad- que son gestionados en el contexto de determinados condicionantes materiales y subjetivos (Villarreal, 2011; véase la noción de juegos en PNUD, 2009). Se ilustra el proceso mediante el cual los agentes sociales construyen dichos marcos en el contexto del sistema de pensiones chileno. Incorporando dicho proceso dentro de una reflexión más amplia sobre la acción económica a partir de la relación entre rutina e innovación, el texto provee una manera de comprender la tensión entre agencia y estructura y los elementos asociados a la elección intertemporal como una relación de condicionamiento recíproco y dinámico.

En la primera sección se desarrolla la relación entre rutina e innovación a la luz de una teoría pragmática de la acción, abordando los elementos que gatillan la construcción de marcos calculativos. A continuación se describen los marcos construidos para tomar decisiones en el sistema de pensiones y sus parámetros de cálculo. En la tercera sección se abordan los

4 El estudio consistió en una investigación cualitativa a trabajadores/as de ingresos personales mensuales de entre $\$ 100.000$ y \$250.000 y edades entre los 45-55 años del Gran Santiago. El trabajo de campo se llevó a cabo de agosto a diciembre de 2010, y consistió en la realización de dos grupos de discusión que sirvieron para recabar discursos emergentes en torno a la jubilación y el sistema de pensiones, seguidos de 32 entrevistas en profundidad. Los participantes en las entrevistas fueron elegidos a través de un muestreo estructural donde

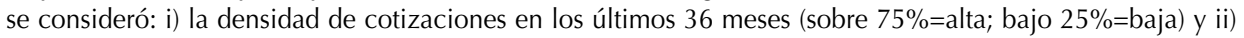
el género (mujer/hombre), dividiéndose la muestra en partes iguales. Se equilibró la muestra por comuna de residencia y se intentó entrevistar personas con densidades altas y bajas dentro de la misma ocupación. 
problemas que la existencia de condicionantes materiales y subjetivos imponen a la gestión de dichos marcos, y los desbordamientos que ellos producen hacia otros ámbitos de la vida cotidiana y mecanismos de generación de ingresos. Los marcos construidos para gestionar el sistema de AFP terminan siendo re-encuadrados e incorporados dentro de estrategias más amplias de generación de ingresos actuales. Ello permite a las personas tomar decisiones efectivas dentro de sus propios parámetros, aunque no siempre exitosas desde el punto de vista del sistema.

\section{RUTINA, INNOVACIÓN Y LOS GATILLANTES DE LA AGENCIA}

Un primer escollo en la comprensión de los procesos de toma de decisiones en un sistema de pensiones como el chileno es cómo conceptualizar la acción. En su vida cotidiana, las personas no están preocupadas de tomar decisiones a muy largo plazo como las relacionadas con la pensión de vejez, e incluso puede que tomen decisiones que la afectan directamente. Ello hace difícil su conceptualización bajo teorías de la elección racional, desde las cuales dicha situación refleja la "miopía" (Barr y Diamond, 2006: 23) de los actores económicos y sus resultados son interpretados a la luz de la inconsistencia de las elecciones intertemporales (Camerer y Loewenstein, 2004). Lo mismo ocurre con teorías sociológicas desde donde la capacidad de los actores de aplicar de manera inteligente los marcos normativos internalizados se limita a lo que permiten las instituciones incorporadas, los recursos circulantes en las redes sociales o sus múltiples incrustaciones [embeddedments] (Dalton, 2004; Beckert, 2003) ${ }^{5}$.

Se ha intentado, en este contexto, revitalizar algunas ideas que permitan tematizar al mismo tiempo la sujeción de las personas a sus entornos de la vida cotidiana y su capacidad para formar parte en procesos altamente contingentes y complejos donde se hace necesaria su participación activa (véanse Schatzki, 1988; Thévenot, 2002; Callon 1998b: 16). Estos conjugan los elementos cognitivos que permiten el aprendizaje y la creatividad (Dalton, 2004; DiMaggio, 1997; Schatzki, 1988) con los elementos sociales y culturales que los determinan (Dequech, 2003).

Teorías pragmáticas de la acción han conceptualizado este fenómeno a través de la idea de saltos entre dos "modos de acción" distintivos: la rutina y la innovación (Beckert, 2003: 775; Joas y Beckert, 2001) ${ }^{6}$. Alejados de las limitaciones de las prácticas rutinizadas, los actores sociales son capaces de redefinir y formatear nuevos mundos de significados a través de procesos de interacción simbólica (Joas y Beckert, 2001: 273 y ss.). Como subraya Dalton (2004) estos dos modos de acción no debieran ser vistos como estrictamente separados, sino constituyendo un proceso social de constante y continuo movimiento entre los polos de la rutina y la creatividad. Los agentes son capaces de ajustar e integrar de manera dinámica

5 Michel Callon se pregunta al respecto: “¿Cómo es que un agente atomizado logra calcular cuando la información que necesita calcular no existe o es contradictoria, o cuando no existen guías institucionales que sean lo suficientemente estables y legítimas, tanto para permitir expectativas compartidas como para hacer manejable un futuro desconocido?" (Callon, 1998b: 6, traducción propia).

$6 \quad$ Esta idea se encontraba ya presente en teorías de la vida cotidiana como la de Schutz bajo la noción de shocks que hacen saltar de un mundo o dominio de la vida a otro (Goffman, 1986: 4). 
soluciones innovadoras a situaciones de sus vidas cotidianas que requieren de marcos de acción y elección novedosos a la vez que normativamente adecuados ${ }^{7}$.

Siguiendo esta idea, denominamos gatillantes a aquellos momentos y/o situaciones que producen quiebres en la vida cotidiana y la abren a incorporar nuevos elementos, en este caso, momentos y/o situaciones sucesivas mediante los cuales las personas comienzan a adquirir la necesidad de preocuparse activamente de su jubilación y la relación con el sistema de pensiones comienza a tomar una relevancia y un sentido específico dentro del contexto de sus prácticas cotidianas ${ }^{8}$. Al quebrar con la rutina, los gatillantes hacen posible la emergencia de modos de acción con mayores contenidos de creatividad y de agencia a través de los cuales nuevos dominios pueden ser incorporados a la vida cotidiana de manera reflexiva.

Dos factores sociales ${ }^{9}$ constituyen fuentes básicas de gatillantes cuando se trata de la provisión de ingresos en la vejez según los testimonios recabados: los ciclos de vida y los medios de comunicación. Los ciclos de vida refieren a la atribución social de significados al paso del tiempo, configurando pautas de rol y expectativas de acción típicas asociadas a diferentes etapas de la vida o ciclos temporales (Huanchuan y Guzmán, 2006; Rodríguez y Rossel, 2009). A nivel individual, se observa la emergencia de gatillantes producto de los cambios drásticos y/o las transiciones entre etapas de la vida. Cambios biológicos marcan el declive y la pérdida progresiva de autonomía física y residencial, así como también cambios en la morbilidad. Las personas comienzan a experimentar enfermedades, o las observan en sus pares de manera más frecuente. Las representaciones sociales sobre el envejecimiento (véase Osorio, 2007) entran en escena cuando las personas asocian la vejez con la enfermedad y la pobreza, generando una conexión entre la preocupación acerca de la provisión de salud y la disponibilidad de ingresos en la vejez:

“Me hice la pregunta cuando fui donde una abuelita que siempre la jubilación... ella jubiló por el mínimo, entonces vive enferma y no le alcanza para comprarse los remedios. O sea ahí empecé a pensar en mí, que me va a pasar lo mismo si no me muevo. Entonces la vi y dije yo: a mí me va a pasar exactamente igual" (Mujer 3, densidad de cotización alta).

Este proceso está marcado también por un cambio en las percepciones sobre el entorno. Llegado un punto cercano a la edad de jubilación, las personas comienzan a interesarse cada vez más en discutir su futuro y atribuir significados relacionados con ella a sus experiencias diarias. Adoptan, así, una disposición a codificar la información que reciben

7 Autores como Thévenot (2002) argumentan que el salto de un tipo de orientación pragmática a otra depende de los arreglos específicos de cada situación, y que la capacidad de interpretar correctamente dichos arreglos constituye uno de los mayores requerimientos que las sociedades contemporáneas imponen a los agentes para participar en ellas de manera exitosa (Schatzki, 1988; véase también Boltanski y Thévenot, 1991). En este texto se pone énfasis en la incompletitud de los marcos de referencia para hacer frente a situaciones radicalmente novedosas, y la necesidad de las personas de completarlos (véase e.g. Callon, 1998b).

8 Cf. La forma y magnitud de los gatillantes en el caso del sistema de pensiones con aquellos que operan en otros ámbitos como las tarjetas de crédito en Barros (2012: 116).

9 DiMaggio identifica también mecanismos cognitivos típicos que permiten transmitir el quiebre en las prácticas cotidianas. Estos serían la atención, la motivación y la falla de los esquemas cognitivos (DiMaggio, 1997: 271-272). 
bajo la perspectiva del envejecimiento, facilitando la emergencia de una reflexión acerca de la pensión de vejez.

De manera más sistemática, diferentes medios de comunicación (formales e informales) constituyen un canal que llama la atención de manera explícita o implícita sobre la necesidad de preocuparse de la jubilación:

“¿Y cuándo cree usted que empezó a pensar sobre cómo están trabajando su plata? Cuando he escuchado las noticias de que han tenido pérdidas las AFP (...). De una crisis que hubo, que las AFP tuvieron pérdidas" (Hombre 4, densidad de cotización alta).

La intensidad de estas llamadas de atención serán determinantes en la fuerza del gatillante. Fuentes y formatos formales de comunicación (por ejemplo la televisión, la radio o el periódico) son más frecuentes pero menos vinculantes que las interacciones cara a cara y especialmente aquellas que se realizan con otros significantes. Finalmente, diversos eventos adicionales pueden constituir gatillantes, como los relacionados al ciclo de vida familiar, o al entorno social más amplio (Hagestad y Dannefer, 2001). En el caso particular de las mujeres, por ejemplo, la muerte del cónyuge o una separación implica muchas veces preocuparse por primera vez de la jubilación o retomar cotizaciones interrumpidas por una salida del mercado del trabajo para hacerse cargo del trabajo en el hogar:

\begin{abstract}
“¿Y cuándo empezó a preocuparse por la jubilación? Del momento de quedar viuda. Del momento en que una queda sola. Entonces, ahí, uno tiene que empezar a ver. Ahí tiene que planificar uno para tener una buena vejez, también. Porque cuando trabajé aquí, la patrona me decía. Y yo decía: 'No, no quiero que me imponga'. Estuve 5 años trabajando, y después perdí po. Yo le decía: 'ahh, yo tengo a mi marido pa ir al médico y todas esas

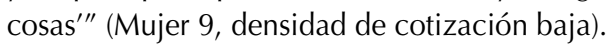

\title{
II. DE LA RUTINA A LA INNOVACIÓN: PROCESOS DE ENCUADRE Y MARCOS DE CALCULABILIDAD
}

Los gatillos abren un período a partir del cual la persona comienza a buscar las pautas de acción y marcos de referencia más adecuados para hacer frente de manera significativa a este nuevo espacio de sus vidas cotidianas. Dada la novedad que constituye un espacio institucional como el sistema de pensiones, y la escasez de conocimiento práctico específico que pudiera ser transmisible desde las generaciones anteriores, los gatillantes marcan el comienzo de una experiencia de involucramiento gradual en la definición de los límites y los parámetros para tomar decisiones en él.

Este proceso gradual puede ser entendido bajo la noción de encuadre [framing](Callon, 1998a, 1998b; Goffman, 1986). Ante la emergencia de un nuevo ámbito de acción, los actores sociales se embarcan en un proceso activo para delimitarlo tanto en sus contenidos normativos y simbólicos como prácticos, de manera de ser capaces de actuar y tomar decisiones en él. Siguiendo a Callon (1998b), para tomar decisiones que implican algún tipo de cálculo, las cosas u objetos, las personas mismas que operan como agentes y las relaciones posibles entre éstos deben ser desenredadas [disentangled] -es decir, desvinculadas de los contextos 
y cosas actuales con que se encuentran relacionadas- y vueltas a enredar-integradas en el nuevo ámbito de acción- definiendo las fronteras de aquello que es y no es relevante para el cálculo (i.e. los parámetros que definen las decisiones y acciones apropiadas dentro del nuevo ámbito) (véase Villarreal, 2011). Los actores sociales, desde esta perspectiva, actúan generando marcos de calculabilidad que les permiten desarrollar acciones, en este caso en un ámbito institucionalizado para la provisión de ingresos en la vejez como el sistema de pensiones. Denominamos gestión previsional al conjunto de acciones referidas a la generación de ingresos para la vejez que son hechas posibles gracias a la construcción de dichos marcos.

En el caso del sistema de pensiones chileno, la capacidad de construcción de marcos de calculabilidad está determinada por elementos materiales y subjetivos que condicionan las posibilidades de gestión previsional. Los primeros refieren a elementos institucionales y estructurales que los agentes no pueden modificar y que inciden en sus capacidades de encuadre, y por tanto afectan el desempeño de la gestión previsional. Además del diseño mismo del sistema, se encuentran entre los más relevantes las trayectorias laborales, el grado y nivel de conocimientos financieros y acerca del sistema de pensiones, y la familia en tanto estructura facilitadora o inhibidora ${ }^{10}$. Los condicionantes subjetivos, por otro lado, refieren a cómo las personas perciben sus necesidades materiales -futuras y presentes-, el grado de interés que desarrollan por la gestión del futuro y su percepción de la efectividad de diversas estrategias o mecanismos de procuración de ingresos (véase Arteaga y Pérez, 2011).

De la combinación de estos elementos se constituyen verdaderos juegos sociales, esto es, "relaciones dinámicas entre elementos institucionales, subjetivos y de conocimiento práctico" (PNUD, 2009: 57) que permiten contextualizar la gestión previsional: un nuevo conjunto de prácticas, los parámetros relevantes para la toma de decisiones, y la evaluación del éxito de dichas acciones. El siguiente esquema tiene por objetivo poner en relación estas dimensiones con la ejecución de diversos tipos de gestión, según los datos relevados por el estudio. Éstos son descritos en detalle en las secciones siguientes, así como el proceso por medio del cual éstas se construyen, se aplican, y su desempeño. El continuo toma como base la densidad de cotizaciones de los entrevistados ${ }^{11}$.

10 La estructura familiar, especialmente la composición y tamaño del hogar y el ciclo doméstico, ha sido estudiada como uno de los determinantes más importantes de las acciones estratégicas que desarrollan familias vulnerables ante eventos de crisis (véanse González de la Rocha, 2006; Kaztman y Wormald, 2002), aun cuando su capacidad de proveer protección ante riesgos se ha visto significativamente disminuida en las últimas décadas por factores culturales (cambios en patrones familiares, especialmente el aumento de las familias monoparentales), económicos (mayor participación laboral femenina), entre otros (CEPAL, 2005: cap. 4). Las características sociodemográficas del hogar moldean el número y tipo de miembros capaces de generar ingresos y las necesidades de consumo, generando fases del ciclo familiar con distintas necesidades y riesgos (CEPAL, 2005: cap. 4).

11 Se encontró que la segunda variable de muestreo, el género, produce diferencias de matiz al interior de cada dimensión, pero no un eje diferenciado que describa la distribución de los datos. Dichos matices son considerados, sin embargo, donde se estimó relevante resaltar las diferencias (cf. Osorio, 2007). 


\section{ESQUEMA 1}

Gestión previsional en trabajadores/as de bajos ingresos, tipos de gestión y sus determinantes

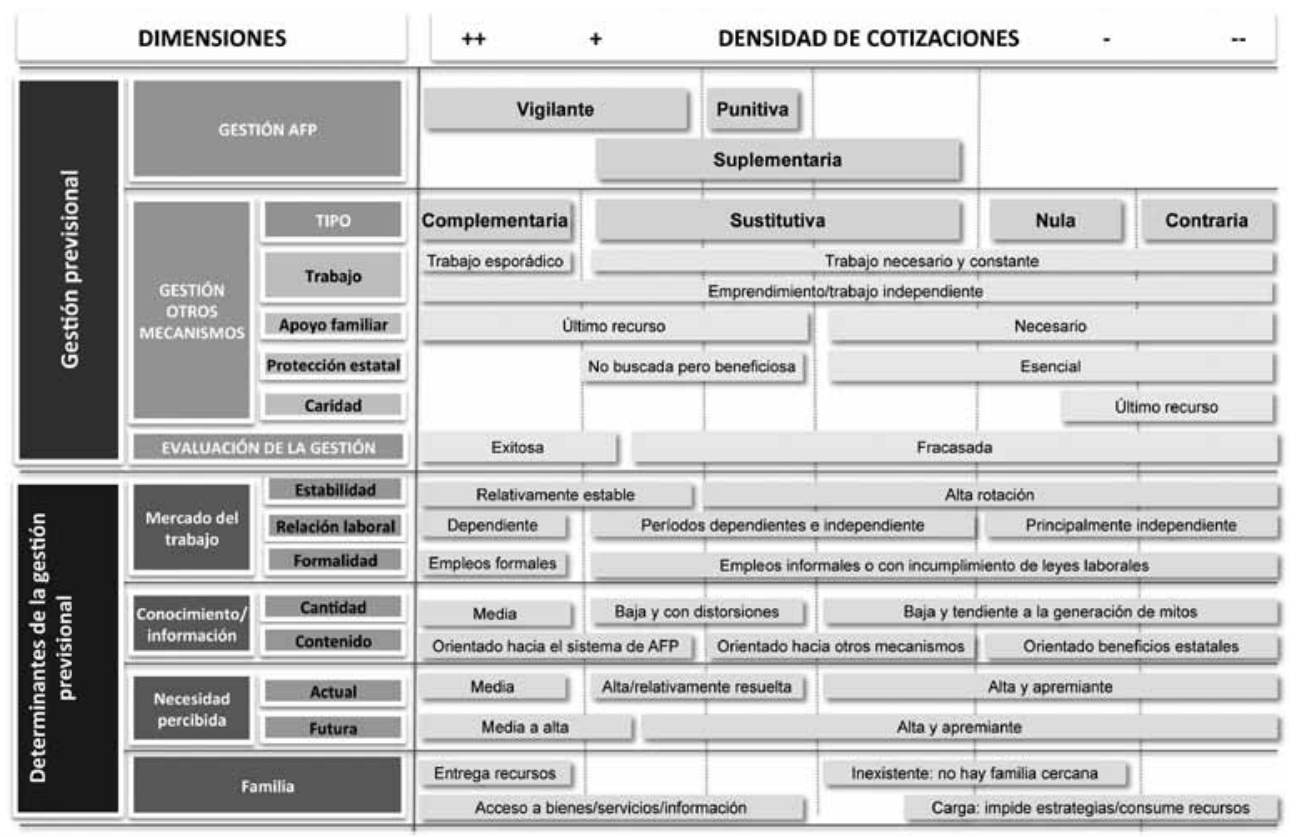

\section{MARCOS DE CALCULABILIDAD PARA EL SISTEMA DE PENSIONES}

\subsection{Encuadre 1: La información}

Si bien hasta el año 2008 únicamente los trabajadores dependientes con contrato de trabajo estaban obligados a cotizar, las personas entrevistadas reconocen a la AFP como mecanismo institucionalizado de protección social para la vejez ${ }^{12}$. Aun cuando las percepciones que se tienen de su capacidad para proveer efectivamente ingresos para la vejez son negativas -pues se comprende que dicha capacidad depende directamente de las trayectorias laborales-, las

12 Si bien los estudios sobre trabajo independiente y previsión social en América Latina recalcan las bajas capacidades de contribución y la baja información de los trabajadores independientes con los sistemas de seguridad social contributivos, se reconoce también la fluidez entre el trabajo independiente y el asalariado, especialmente en grupos vulnerables (Bertranou, 2007; Tokman, 2007), situación que explica su conocimiento del sistema de pensiones y su vínculo con él a través de cotizaciones esporádicas cuando se encuentran en empleos formales. En Chile, la permanencia media en el empleo alcanzaba en 2004 a 5,5 años y un 34,5\% de los trabajadores permanecía en su trabajo menos de un año (Tokman, 2007: 15). Así, en 2005 alrededor del 20\% de afiliados a la AFPs no presentaban cotizaciones en los últimos cinco años (CENDA, 2005: 26). Esta dinámica ha sido confirmada por estudios cualitativos sobre trayectorias laborales de familias de bajos ingresos (PREDES, 2006). 
personas muestran una determinación importante por aumentar la información que poseen de dicho mecanismo ${ }^{13}$ :

"Yo por eso te digo, a mí me gustaría que alguien me asesorara, pero que no sea engañador, que no me engañe" (Hombre 3, densidad de cotización alta).

Las personas son selectivas y asignan distintos grados de relevancia a distintas fuentes y formatos de información, lo que repercute de manera diversa en la construcción de marcos y el desempeño de la gestión (véase también Barros, 2012). Uno de los canales de información más importantes son las visitas personales a las sucursales de las AFPs, que sin embargo cuenta con una limitación importante relacionada al código utilizado para comunicarla. La mayor o menor distancia con este código genera reacciones que condicionan la disposición de las personas ante el sistema e influye en las modalidades de gestión adoptadas (cf. Subsecretaría de Previsión Social, 2008). Prevalecen, en este sentido, las evaluaciones negativas hacia un sistema que se presenta ajeno y hostil ${ }^{14}$ :

"Tiene que ver con el vocabulario que se expresa, es muy técnico. O sea, para el común de la gente es demasiado técnico... la forma en que vienen los documentos para explicar todo el tema es demasiado técnico. Entonces, para nosotros el común de los cristianos no entendemos" (Mujer 5, densidad de cotización alta).

"La información es súper por encima, no es una información que te hagan comprender de qué se trata tu plata y qué pasa con tu plata (...). Por ejemplo, uno no sabe si la AFP de uno está invirtiendo y dónde está invirtiendo; uno no tiene idea cómo se desenvuelven los dineros nuestros todos los meses. Porque no creo que lo estén echando en una cajita que diga [su nombre], y esta es la plata de ella (risas), o estén comprando barritas de oro para que uno no pierda la valuación del dinero. No creo que sea así. Se supone que ellos manejan y juegan con la plata, esa información uno no la tiene cabalmente" (Mujer 1, densidad de cotización alta).

La segunda fuente de información más importante, y la mejor evaluada, es aquella que proviene de cercanos con conocimientos sobre el tema, es decir, que combina la conversación cara a cara con un lenguaje informal. Estos pueden ir desde encuentros y conversaciones esporádicas sobre el tema, hasta situaciones en que se configura una verdadera red que permite hacer circular información desde un centro que en general es una persona que tiene más conocimientos. En estos casos, la búsqueda de información puede llegar a rutinizarse:

"Mira, ahora por ejemplo, el John que es mi jefe me ha estado enseñando cómo son las cosas, cómo tengo que hacerlo. Por ejemplo, uno va a la AFP y uno pide, como se llama esta cuestión del internet, y te dan un número ellos, y tú averiguas tu cotización; si te la están pagando, si está bien" (Hombre 14, densidad de cotización baja).

13 Esto se contrapone a la afirmación de Berstein y Ruiz respecto de que "los afiliados no entienden el sistema de pensiones, ni de qué forma deberían participar en sus decisiones y tampoco están interesados en entender" (2005: 5, cursivas añadidas).

14 Una situación límite que ejemplifica esta distancia es cuando se estimula a las personas a utilizar internet como fuente de información. Dado que en la mayor parte de los casos los entrevistados no tienen acceso, no lo entienden, ni tampoco lo saben usar, se llega a situaciones en que ni el código ni la fuente facilitan la información. No obstante este tipo de lenguaje, las personas no dejan de utillizar a la AFP como canal de información. 
La ventaja más grande de las fuentes informales no tiene que ver tanto con la mayor accesibilidad del código, sino en la confianza y la credibilidad que se les atribuye. Se entienden como ayudas honestas y bien intencionadas, por oposición a las fuentes más institucionalizadas que en general tienden a gatillar los sentimientos opuestos de incredulidad y desconfianza. Adicionalmente, proveen conocimientos e información no sólo sobre la AFP sino también sobre un conjunto de prácticas y estrategias alternativas que, como veremos más adelante, en la mayor parte de los casos se transforman en los puntales de la gestión previsional. Estos, sin embargo, tienen el inconveniente de ser limitados en su extensión, calidad y precisión.

\subsection{Formateo 2: Los parámetros}

Tres parámetros son los más utilizados como herramientas para definir el tipo de gestión a realizar: la cantidad acumulada en el fondo de pensiones, los retornos de las inversiones de dicho fondo y el servicio al consumidor brindado por la AFP.

Los dos primeros son comunicados de manera regular y por ley a todos los cotizantes por medio de balances escritos que son enviados por correo. Las personas pueden también solicitar una clave de internet y acceder a sus datos -historial de cotizaciones, simulaciones de pensión- electrónicamente. El primer parámetro se controla indirectamente también a través del historial de cotizaciones:

"Lo que más me interesa es que vaya el pago al día. Porque sí, me pasó en una oportunidad que, años atrás, que llevaba tres años y de los tres llevaba como siete meses impago (...). Entonces eso, lo que le llamaban laguna y todas esas cosas. Pero eso lo que me conlleva igual a informarme de la información que me envían" (Hombre 7, densidad de cotización alta).

Este es fundamental pues determina una evaluación previa de las posibilidades de utilización exitosa del sistema de pensiones. Así, las personas comprenden que niveles bajos del fondo y lagunas de cotización se asocian con trayectorias laborales inestables y bajos niveles actuales de ingresos, y por tanto perciben una situación de mayor apremio económico en el futuro. Esta evaluación de la necesidad futura, y de las posibilidades de utilización exitosa del sistema de pensiones, son fundamentales para explicar la mayor o menor incidencia que tiene este mecanismo en distintas experiencias previsionales.

El segundo parámetro no se utiliza en función de una comparación racional de los retornos de los fondos en distintas administradoras, sino que se evalúa en función de la comparación con una variación esperada, no necesariamente cuantificable o racionalizable:

"Me acuerdo que en ese tiempo me di cuenta que tenía mayor, no sé si se llama... rentabilidad. Estaba en mejores condiciones, ofrecían mayor estabilidad" (Mujer 5, densidad de cotización alta).

El tercero, por último, corresponde a la apreciación que las personas hacen de la atención que reciben cuando acuden a la AFP, principalmente a solicitar información: 


\begin{abstract}
“De las otras me he cambiado por mala atención (...). Porque te ven, y como andes vestido te van a tratar. Una vez me pasó eso, y yo la quedé mirando a la señorita. Me tocó una persona que tenía... no era despreciarlo, pero él llevaba dos millones, y lo atendió primero. Y yo que estaba antes que él... Entonces en el momento me dio rabia, dije: 'no po'" (Hombre 5, densidad de cotización alta).
\end{abstract}

\title{
3.3. Formas de gestión del sistema de pensiones
}

Tomando en consideración la información obtenida de diversas fuentes y los parámetros relevantes recogidos de ellas, se construyen marcos típicos para la gestión del sistema de pensiones. Denominamos gestión vigilante a aquella que consiste en un chequeo relativamente periódico de los parámetros básicos del sistema para estar al tanto de potenciales riesgos. Esta tiende a aparecer luego del conocimiento de un evento que perjudica al cotizante mermando sus fondos, por ejemplo enterarse de que el empleador no paga las cotizaciones, una pérdida de valor del fondo o mala atención en la AFP. La gestión vigilante se manifiesta en acciones como el seguimiento de la rentabilidad del fondo o la comprobación del pago de las imposiciones:

"Yo siempre estoy controlando si la empresa me está pagando. Cada dos meses hago un chequeo (...). Me fijo si están las imposiciones todas al día, y lo que gano yo, y veo cuánto han depositado. Y veo cuánto he ganado cada seis meses. Un control que yo llevo donde estoy" (Hombre 5, densidad de cotización alta).

Denominamos gestión punitiva a una acción de castigo que muestra la adopción de la lógica del consumidor con respecto al sistema de pensiones, donde la respuesta por defecto de la persona es un cambio de AFP. Existen dos parámetros que pueden gatillar este tipo de gestión. Por una parte, el mal servicio de atención al cliente de la AFP y/o la desconfianza en la información provista (impresión de estar siendo engañado/a), y por otra, los malos resultados financieros en la administración de los fondos. Así, enterarse de que los fondos previsionales tuvieron una caída considerada importante, o una experiencia de mala atención cuando se acude a solicitar información, pueden provocar una acción de castigo que se traduce en el cambio de AFP:

"Me dio rabia, porque tú sabes, las AFPs trabajan el dinero de una. Tuve una pérdida y me descontaron como un millón de pesos. Salí pa' atrás... un descuento de un millón de pesos... Y no podía ser, porque estoy perdiendo plata po. Si tú estas cotizando para tu vejez, ¿por qué tienes que pagar los platos rotos?, si es tu plata. Entonces me dio rabia y me cambié" (Mujer 7, densidad de cotización alta).

La gestión punitiva no es sistemática en términos de su aplicación, sino que depende de hechos específicos. En otras palabras, las personas no se cambian de AFP cada vez que los atienden mal o cada vez que se enteran que los fondos bajaron ${ }^{15}$. En efecto, el cambiarse

15 El estudio de Berstein y Ruiz (2006) muestra que hasta 2001 aproximadamente los cambios de AFP eran frecuentes debido a la competencia entre AFPs por captar nuevos afiliados a través de agentes de ventas, llegando a materializarse un máximo de 1,6 millones de traspasos anuales en 1997 (12). En línea con la 
de AFP es percibido como un proceso engorroso, lo que dificulta la realización de esta estrategia. Por ejemplo, hay personas que perciben que al cambiarse no se les reconocieron las cotizaciones realizadas en otra AFP, o que les cobraron comisiones al traspasarse, lo que hace difícil e impredecible los resultados del cambio.

Otro elemento a considerar es que los parámetros utilizados para el cambio están fuertemente determinados por las percepciones propias, por ejemplo sobre qué nivel de caída en los fondos es considerado aceptable o inaceptable, o sobre cuál es considerada "la mejor AFP" para cambiarse. En este sentido, es difícil hacer explícita la justificación de la opción elegida y muchas veces dicha elección pasa por percepciones que no suponen una aplicación de criterios estrictos de evaluación ${ }^{16}$. Una justificación que tiende a repetirse entre quienes cambian de AFP es cambiarse a la "AFP del medio", lo que puede interpretarse como una forma de reducir la complejidad asociada a la toma de decisiones y la aversión al riesgo cuando se dispone de poca información y conocimiento sobre los elementos relevantes a considerar en las alternativas posibles. También indica la credibilidad asociada a las fuentes de información informales:

“Uno desconfía mucho de las propagandas de la televisión. Y te ponen una AFP que gana mucho y que tiene un índice de utilidades mayor que otra, y habrá que creerle. Pero uno como un ciudadano de clase media desconfía de la publicidad, y si me dicen que Cuprum es la más alta, yo creo un 50\%, y prefiero quedarme donde está la masa, Provida, y ahí como una oveja más del rebaño. Si gano, no va a ser mucho, pero si pierdo tampoco va a ser mucho" (Hombre 9, densidad de cotización baja).

A diferencia de las acciones punitivas, las acciones vigilantes por lo general no suponen cambios de AFP, sino sencillamente una especie de estado de alerta y un monitoreo constante. En este sentido, lo que define a ambos tipos es la actitud que la persona asume ante los eventos que afectan los parámetros relevantes. Las acciones punitivas están marcadas por una reacción activa y drástica ante ciertos eventos que pueden presentarse de manera irregular. En cambio, las acciones vigilantes tienden a tener un mayor nivel de regularidad, aunque gatillan reacciones que tienen menos consecuencias directas para la situación previsional (por ejemplo, mayor vigilancia). Este carácter pasivo de la acción vigilante es signo de una mayor estabilidad laboral debido a que los cambios en el fondo de pensiones no son percibidos como acontecimientos. En el caso de la acción punitiva, en cambio, la mayor lejanía con la situación previsional hace que las personas interpreten de manera más dramática las noticias que reciben.

Una tercera variante que hemos denominado gestión suplementaria consiste en el incremento del nivel actual del fondo. Al enterarse del nivel acumulado en la cuenta de

tendencia observada a la caída de dicho fenómeno en los años siguientes, los testimonios recabados muestran que los cambios no son frecuentes en la actualidad.

16 También se obtuvieron relatos que explican los cambios producto del ofrecimiento de regalos por parte de los vendedores o agentes de las AFPs. La información obtenida al respecto coincide con Berstein y Ruiz (2006) y su observación de que alrededor del $30 \%$ de los cambios de administradora se realizaban por motivos distintos a los esperados por el sistema -rentabilidad de los fondos y comisiones de administración-. 
capitalización individual, las personas manifiestan la intención por aumentar los fondos poseídos ya sea aumentando el monto y/o la frecuencia de la cotización, o utilizando el mecanismo de ahorro previsional voluntario. Según consta en los relatos, esta opción se ha ampliado notoriamente debido a la introducción de la Pensión Solidaria y los incentivos que ésta ofrece a la cotización. No obstante, dado que esta estrategia depende de la inserción actual en el mercado del trabajo, no llega a concretarse y permanece en el nivel del discurso y de la deseabilidad. En efecto, en aquellos casos que la mencionan como estrategia, se observa una postergación constante de su inicio. En otros, se manifiesta que el posible aumento en la pensión producto de dicha gestión no compensa el sacrificio que esta implica en términos de sacrificar consumo presente. Las razones de que ésta no logre llegar a configurarse son parte de la sección siguiente referida a los desbordamientos de los marcos calculativos:

"Bueno, yo pienso que uno tiene tantas cosas que hacer... en este momento uno tiene prioridades, pero pienso más adelante en hacer una cotización aparte, de esas que tiene la AFP. Una de esas que también... una que también te descuentan un adicional, tener un poco más de plata. Pero todavía no porque estoy con deudas. Con deudas que tengo ahí (risas)... ya cuando salga de las deudas..." (Mujer 7, densidad de cotización alta).

\section{DESBORDAMIENTOS [OVERFLOWING]}

La gestión del sistema de pensiones como mecanismo de generación de ingresos para la vejez se hace posible i) gracias a la existencia de gatillantes que permiten romper con la rutina y dar paso a modos de acción con mayor contenido de reflexividad, permitiendo ii) la construcción de marcos de calculabilidad que involucran la información obtenida de diversas fuentes y los parámetros que con ella se establecen. La mantención de estos marcos, sin embargo, se hace cada vez más difícil debido a que sus fronteras se vuelven porosas a los condicionantes materiales y subjetivos que les subyacen. Esto se manifiesta, por ejemplo, en la incorporación de nueva información sobre otros mecanismos de protección social más efectivos que el sistema de pensiones, la existencia de otros parámetros que afectan el éxito de las acciones emprendidas (por ejemplo, decisiones tomadas por terceros), o la existencia de otros objetivos económicos en contradicción con la obtención de una pensión, a saber, la obtención de ingresos presentes. Siguiendo a Callon (1998a, 1998b), denominamos a estos procesos desbordamientos [overflowing] ${ }^{17}$. De acuerdo al autor, son los mismos elementos que permiten el encuadre y estabilización de las acciones los que proveen conexiones a otros mundos, abriendo con ello un vínculo a otros objetos y prácticas (Callon, 1998b: 18). En este sentido, los procesos de encuadre nunca pueden ser completos, dado que los objetos y relaciones dispuestos bajo un determinado marco no pueden ser completamente desenredados de los significados y usos que asumen en otros marcos.

17 La metáfora más directa que el autor ofrece sobre los procesos de desbordamiento es lo que ocurre en la esfera de la producción con la generación de externalidades, esto es, efectos no esperados de la realización de una serie de rutinas organizativas y productivas (i.e. marcos de calculabilidad), que tienen efectos sobre ellas y obligan a su reorganización. Esta reorganización que pretende reincorporarlas nunca puede ser completa ya que siempre habrá la posibilidad de nuevas externalidades que escapen a la posibilidad de cálculo. 
A continuación describimos los desbordamientos observados y cómo ellos afectan la gestión del sistema de pensiones.

\subsection{Desbordamiento 1: Rigideces y deficiencias institucionales}

Además de los condicionantes materiales y subjetivos mencionados, un elemento fundamental que define la capacidad de gestión del sistema de pensiones es el diseño del sistema propiamente tal. Pudimos encontrar ejemplos de dos elementos que marcan la coerción del diseño del sistema sobre la aplicación efectiva de los marcos descritos: las decisiones de terceros y su rigidez para aceptar estrategias innovadoras.

El primero de ellos refiere al poder que asume el empleador en tanto mediador de la relación entre el trabajador y la AFP en lo que refiere a la cotización. Este se traduce en la capacidad de obligar ciertas elecciones, especialmente asociadas a la AFP en la que se cotiza, lo que constituye un limitante generalizado a la gestión del sistema en trabajadores/as de bajos ingresos. Esto produce efectos sobre la información que se tiene del funcionamiento del sistema (por ejemplo, generar la impresión de que las empresas están ligadas o "trabajan" con determinadas AFPs), por lo que es la empresa la que decide en qué AFP se debe estar. Esto impacta directamente en las posibilidades de éxito de los marcos construidos y en la confianza en la efectividad de los mecanismos institucionalizados de generación de ingresos para la vejez:

\footnotetext{
"Cuando yo entré a trabajar yo dije que estaba en Hábitat. Y me empezó a cotizar este caballero en la tienda que estuve en Patronato. Estuve un tiempo ahí y después ahí mismo me cambié a Provida porque era como de un estorbo, o algo así... que tenía que hacer una papeleta aparte el contador para yo solamente que estaba en Hábitat y el resto que estaba en Provida. Entonces me llama un día y me dice que me cambie a Provida porque es lo mismo, y para que todos los del trabajo estemos en esa misma. Y yo inocentemente me cambio. Porque no sé, yo te digo, no sé mayormente si me perjudicó o no, no tengo idea. Me cambié y ahí quedé, y después en los siguientes trabajos seguí cotizando en la misma" (Mujer 4, densidad de cotización alta).

"Yo estuve un tiempo en el sur, y en el sur me pusieron en Provida, y yo estaba en Hábitat. Ellos me cambiaron a Provida. Ellos 'trabajaban' con Provida, una cosa así. Y ellos, por la de ellos, me pusieron en Provida" (Hombre 10, densidad de cotización baja).
}

En segundo lugar, la rigidez del marco legal limita las posibilidades de transformar el fondo de pensiones en una alternativa más cercana a las necesidades percibidas actuales y futuras de las personas. Las modalidades de jubilación ofrecidas están fuertemente normadas, ofreciéndose grosso modo dos posibilidades: una pensión vitalicia, esto es, el traspaso de los fondos acumulados a una compañía de seguros a cambio de lo cual ésta ofrece una pensión de por vida, o el retiro programado, es decir, el retiro mensual de una pensión cuyos montos se establecen dividiendo el fondo acumulado por la expectativa de vida de la persona, que deja de percibirse una vez que se consume el fondo. La decisión entre una u otra no es estrictamente individual, pues se requiere un nivel mínimo de capital 
acumulado para acceder a la primera. Los trabajadores de bajos ingresos se ven, de este modo, obligados a tomar la segunda.

Ello, sin embargo, lejos de ser asumido de forma pasiva, genera ideas innovadoras acerca de cómo el sistema de pensiones puede ser utilizado de manera más cercana con sus propias necesidades y aspiraciones ${ }^{18}$. Recibir una pensión bajo la modalidad retiro programado constituye una opción subóptima pues el flujo de ingresos que genera es muy bajo como para ser relevante ${ }^{19}$; en cambio, considerado en su conjunto, el fondo acumulado constituye una cifra importante que puede utilizarse para mejores fines. De esta reflexión surge una alternativa innovadora. Esta implicaría jubilar anticipado, retirar el total de los ahorros depositados hasta el momento en el fondo previsional y utilizarlos para comenzar un microemprendimiento u otra actividad independiente. Dadas las altas tasas de rotación laboral, sumado a la dificultad de encontrar trabajo entrando en edades medias y avanzadas (véase Bertranou, 2007: 5), ello supone una solución eficiente para la preocuración de ingresos presentes y futuros. El trabajo independiente, por otro lado, fortalece la identidad y autonomía de las personas, ofreciéndoles una opción que les resulta flexible y cómoda para sus propósitos de generación de ingresos (véase Tokman, 2007: 23-24):

"El dinero que ellos me sacan obligatoriamente, no lo encuentro que para ciertas clases de trabajadores sea muy provechoso. Para nosotros, con todas las reglas que ellos imponen, que yo tengo que jubilar a los 65 años, creo que eso debería ser una opción personal. Porque si yo estoy metiendo plata en un lugar para mi vejez, debiera yo decidir cuándo jubilo. Y entendiendo que cierta cantidad de plata me van a dar, y que yo dijera: 'sabe qué, quiero de 100 lucas mensuales; sabe qué, quiero de 20 lucas mensuales', dependiendo de mi necesidad. Pero ellos me obligan a ciertas cosas que no están dentro de mis necesidades y me parcializan la plata a comodidad de ellos, no a la mía" (Mujer 16, densidad de cotización baja).

"Que la plata uno la pudiera sacar toda (...). Por supuesto, que ahora que no podai sacarla, pero cuando te jubiles que puedas sacar toda tu plata y invertirla... no sé po, en lo que tú pienses. O por último una parte, la mitad a lo mejor, para poder trabajarla" (Hombre 14, densidad de cotización baja).

Existe también una razón más de fondo para dicha alternativa relacionada con cómo perciben las personas el funcionamiento del sistema de AFP. Para muchas, el ahorro previsional constituye un ahorro forzoso, dado que si tuvieran la posibilidad de no hacerlo preferirían utilizar ese dinero en el presente tanto para sustentar nuevas estrategias de generación de ingresos, como para consumo corriente y para hacer frente a gastos imprevistos (por ejemplo, enfermedades). Lo anterior se exacerba con el poco conocimiento que tienen del funcionamiento del sistema, que los hace tener desconfianza y tener la sensación de que su dinero se está perdiendo. También se mezcla con las pocas perspectivas de futuro que

18 Resulta relevante destacar que, al hacer esta reflexión, los entrevistados se autoperciben como una categoría particular de la población trabajadora, argumentando que la alternativa propuesta pudiera no ser igualmente eficaz para otras categorías de trabajadores (por ejemplo, aquellos con mayor capacidad contributiva). 
tienen, Ilegando incluso a imaginar la posibilidad de nunca llegar a utilizar esos ahorros producto de una muerte prematura, o porque el mal manejo de las administradoras los deje finalmente $\sin$ fondos $^{20}$ :

"Y si a mí me pasa algo el día de mañana, ni Dios quiera, y esa plata ¿pa' dónde se va a ir? Se van a quedar ellos con la plata, los de la AFP. Por eso no me gusta y trato de pelear para que me la devuelvan. No importa que después no tenga nada, si total, a lo mejor a los 65 años, como te digo, a lo mejor no voy a estar. Así que por eso yo trato de ir. No he podido ir porque ahora que estoy cesante no tengo plata para nada, o si no iría pa ver qué solución me pueden dar. Por último que den un pago de cesantía" (Hombre 11, densidad de cotización baja).

“¿Qué promedio de vida vive una persona en Chile? 67 años. Acaso llega. ¿Qué vai a disfrutar de tu plata? Nada. Te moriste, la plata queda ahí. Y el sacrificio, ¿quién se lo lleva? Ellos, ellos se llevan toda la plata. Porque si tú tuvieras una enfermedad, por ejemplo, la misma enfermedad que tiene mi cuñado: tiene cáncer, él se va a morir. Tiene 25 millones en la AFP (...) ¿por qué no le pasan la mitad de la plata que le sacaron toda la vida?" (Hombre 12, densidad de cotización baja).

\subsection{Desbordamiento 2: Cualificación de bienes/servicios}

Una de las afirmaciones principales de la sociología económica es que para que el cálculo -y el intercambio- tenga lugar, los objetos en juego deben ser formateados en tanto bienes o servicios susceptibles de apropiación; deben hacerse disponibles para el intercambio de mercado, esto es, establecer expectativas recíprocas entre los agentes de mercado, permitir una estabilización momentánea de las preferencias respecto de ellos, entre otros (Callon y Muniesa, 2005: 1232 y ss.; Çalışkan y Callon, 2010: 5 y ss.). Este proceso de cualificación o de "inversión en formatos" (Thévenot, 2002) ha sido también reconocido por la economía de los costos de transacción, para la que los atributos que hacen a un objeto un bien de intercambio, y las características que este posee y que lo hacen un objeto de deseo por parte de un comprador, no son evidentes y requieren esfuerzos -costosos- para develarlas (North, 2006).

Dos problemas surgen respecto de la cualificación de la pensión de vejez que generan desbordamientos. En primer lugar, existe una importante falta de definición de los derechos de propiedad, pues, aunque los trabajadores/as son formalmente dueños de sus fondos, la fluctuación de su valor los hace altamente impredecibles. Las personas no pueden calcular de manera sencilla el valor futuro de sus fondos de pensiones, especialmente en el contexto de shocks económicos y financieros constantes. Por otro lado, las personas se muestran suspicaces de la manera en que los fondos son manejados, y aun cuando realicen gestiones

20 La inexistencia de esta alternativa subraya, adicionalmente, las relaciones de poder incrustadas en las instituciones, que definen por tanto los procesos de formateo y valoración [valuation] (Callon y Muniesa, 2005: 1237-1239; Çalışkan y Callon, 2010: 13). La existencia de restricciones legales que limitan los procesos de formateo que llevan a cabo los trabajadores de bajos ingresos demuestra no sólo una distribución desigual de los marcos calculativos, sino también del poder para construirlos y modificarlos. 
de tipo vigilantes o paliativas, como se vio anteriormente, conservan la sensación de que no poseen el control de los resultados de sus fondos de pensión. Adicionalmente, las deducciones mensuales de sus salarios -cuando están en trabajos formales- y el horizonte de largo plazo asociado a los resultados de la inversión del fondo de pensiones los pone ansiosos, pues ven sus recursos malgastados en condiciones que podrían utilizarlos para consumo actual:

\footnotetext{
"Me molestaría [que mi fondo perdiera dinero] porque no es mucho lo que tengo y más encima, te están sacando más... no sé, por un mal negocio, por así decirlo. Yo no sé en qué invirtió ese mes, que cayó la bolsa y se fueron todas las letras A o B abajo. Pero como te digo, no sé ni en qué letra estoy" (Mujer 2, densidad de cotización alta).
}

En segundo lugar, existe un problema más profundo en relación a la dificultad que implica identificar para qué es exactamente que tienen que calcular y gestionar el sistema de pensiones. Cuando visualizan el objetivo de sus acciones, emergen tres significados distintos acerca de lo que involucra una pensión de vejez: el futuro, la vejez y la jubilación. En tanto noción abstracta, el futuro se presenta como una proyección del presente. Dada la vulnerabilidad económica de los trabajadores/as de bajos ingresos, tiende a prevalecer la inmediatez de la planificación económica. El manejo de la situación presente de escasez y vulnerabilidad implica una preocupación por un futuro más estricto, limitado a lo que puede obtenerse con los recursos disponibles:

"Uno va a lo que va llegando nomás... a lo que a medida que va pasando el tiempo nomás. Y llegado el tiempo, bueno, ahí se va a ver qué se va a hacer. Pongámosle que yo todavía trabajo, yo cuido al nieto, entonces, si llega el momento ahí veo si imponemos, qué hacemos (...). Si al final uno trabaje lo que trabaje va a ser casi lo mismo nomás de pensión" (Mujer 12, densidad de cotización baja).

Por otro lado, la vejez constituye una etapa del ciclo de vida fuertemente cruzada por consideraciones culturales y representaciones sociales. La imagen del envejecimiento, en tanto proceso, es influenciada por la manera dramática como lo muestran los medios de comunicación y es confirmada a diario en la interacción de estas personas con otras de diferentes edades. La imagen aprehendida produce predicciones temerosas y dramáticas acerca de la vejez: abandono, soledad, desprecio, vulnerabilidad, pobreza, enfermedad, pérdida de independencia. En este sentido, la vejez se transforma en aquella etapa a la que no se quiere llegar. La vejez es relegada como una etapa residual de la vida, aquella en que las personas ya no tienen las fuerzas o salud necesaria para llevar una vida digna -asociada al trabajo-:

"Lo que pasa, que la sociedad en que vivimos en este país ser viejo no es bueno. Ser viejo es gastos, soledad, es vivir pobre, esa es la valoración que se tiene (...). Porque tú no piensas que la vejez puede ser: 'ah, yo termino, jubilo y viajo, y me dedico a conocer por Chile los lugares que yo quería'. No po, no es así. Pensamos que vienen las enfermedades, que hay que gastar plata en el médico... Lo que uno escucha en la tele cuando entrevistan a la gente, a los que entrevistan dicen siempre los pensionados: 'es poco, yo gano poco, apenas me sirve' (...). Yo creo que todos tenemos esa visión de la vejez en Chile, una vejez paupérrima (...) por eso preferimos no acercarnos a ella, o sea mientras más lejos esté, mejor" (Mujer 1, densidad de cotización alta). 
“O sea, yo he pensado en la jubilación, sí, pero en dejar de trabajar no. Y en la vejez, yo le llamo cuando uno no pueda hacer nada" (Hombre 4, densidad de cotización alta).

La jubilación, por último, se entiende en contraste con el trabajo. Se asocia a un proceso de administración económica fuertemente condicionado por la relación con el mercado del trabajo y estructurado en función de las alternativas ofrecidas por el sistema de pensiones y otras formas institucionalizadas de obtener la jubilación (por ejemplo, las pensiones estatales). El problema en términos de desbordamiento surge de las contradicciones entre una jubilación ideal -la posibilidad de ganar estabilidad, independencia y autovalencia-y aquella que las personas perciben como su realidad más cercana, esto es, la necesidad urgente de encontrar mecanismos alternativos de protección social dadas las limitaciones de aquellos institucionalizados (véase también Bertranou y Casalí, 2007: 128-129):

\begin{abstract}
“Dios dirá en el momento en que tú necesites salir a recrearte. ¿Por qué no puedes sacar un pasaje? ¿o un hijo que te regale un pasaje? (se ríe) ¿cómo sabí si dicen: 'mamá, sabí que te traigo de regalo un pasaje en avión'? ¿Cómo no va a faltar? (...). Pero yo creo que no, no estoy programada, ni me hago proyectos así en el aire. No, yo soy bien realista, yo pienso que tengo que seguir trabajando, no sé, hasta cuando Dios diga basta nada más" (Mujer 2, densidad de cotización alta).
\end{abstract}

\title{
4.3. Desbordamiento 3: La omnipresencia del presente
}

La tercera fuente de desbordamiento dice relación con la imposibilidad de escapar a los determinantes materiales de la acción. En este sentido, la contribución al fondo de pensiones y el desarrollo de acciones para su gestión no pueden des-enmarcarse de las fuentes de ingresos actuales, negando así -o haciendo más difícil- la posibilidad de planeación o cálculo en el largo plazo. Dado el contexto de vulnerabilidad socioeconómica y empleos inestables, la preocupación por aumentar el nivel actual del fondo de pensiones de manera de obtener una mejor pensión en el futuro se ve fácilmente superada por la necesidad de diseñar estrategias para generar ingresos en la actualidad. De este modo, la preocupación se transforma rápidamente hacia las fuentes de procuración de ingresos en general, dejándose a un lado aquellas referentes en específico a los ingresos en la vejez:

\footnotetext{
"Si yo pudiera cotizarme yo mismo, imponerme yo mismo, lo haría. Pero las circunstancias no me han dado para poder hacerlo. Yo podría poder imponerme trabajando independiente, ¿me entiende?, pero no se me han dado los medios" (Hombre 10, densidad de cotización baja).
}

\section{RE-ENCUADRANDO LA ACCIÓN: DE LA INNOVACIÓN A LA RUTINA}

Los procesos de desbordamiento como los recién descritos tienen la capacidad de i) romper con los marcos construidos para gestionar el sistema de pensiones, y ii) llamar la atención sobre la necesidad de generar ingresos en el presente. La gestión del sistema de pensiones es ampliada, de este modo, y subsumida bajo la noción más general de las estrategias diseñadas por las personas y familias para obtener ingresos en el presente, 
y aquellas que se aplican en situaciones no cotidianas como los eventos de crisis. Dos procesos de re-encuadre tienen lugar: por un lado, a las estrategias actuales es incorporada una preocupación -realizada o no- por la vejez en términos genéricos; por otro lado, a la gestión de la vejez propiamente tal se le añaden componentes de la gestión de ingresos actual. En referencia a esta última, el resultado es la utilización de estrategias que ya han sido probadas como eficaces para la generación de ingresos en el presente y el pasado. A partir de ello se reconfiguran los marcos de calculabilidad en formatos más amplios conformando una especie de repertorio de prácticas adecuadas a la generación de ingresos en distintos momentos de la vida (cf. Barros, 2012). Así, la ruptura de la rutina generada por los gatillantes no logra constituir un modo de acción completamente innovador dada la existencia de diversos condicionantes materiales y subjetivos. Los horizontes de acción se repliegan y cristalizan en nuevas prácticas que incorporan los repertorios actuales. La dinámica de los procesos de desbordamiento hace que dicha cristalización constituya una fusión entre elementos innovadores (parámetros, lógicas de cálculo, ámbitos de acción) y elementos conocidos (prácticas efectivas de generación de ingresos).

\subsection{Re-encuadre 1: Fuentes de generación de ingresos alternativas}

Kaztman y Filgueira (1999: 9) denominan estructuras de oportunidades a las "probabilidades de acceso a bienes, a servicios o al desempeño de actividades (...) [que] inciden sobre el bienestar de los hogares, ya sea porque permiten o facilitan a los miembros del hogar el uso de sus propios recursos o porque les proveen recursos nuevos". La capacidad de las personas de utilizarlas no depende únicamente de su existencia objetiva, sino también de cómo estas son percibidas (Arteaga y Pérez, 2011), lo que incide directamente en si y cómo estas son utilizadas como estrategias de generación de ingresos para la vejez (véanse Huanchuan y Guzmán, 2006). Estas se combinan de distintas maneras para formar nuevas formas de gestión, teniendo como referencia el fallo en la gestión del sistema de pensiones.

Por lejos, la estrategia que los entrevistados evalúan con mejores posibilidades de convertirse en un mecanismo de generación de ingresos para la vejez es el trabajo, ya sea continuando el actual u otro. Este resulta la estrategia más plausible pues se asocia a la experiencia previa de haber tenido que buscar distintas formas de generación de ingresos durante sus vidas, especialmente en las mujeres. En este sentido, representa la aplicación de soluciones que las personas han encontrado más efectivas para obtener ingresos en otros contextos (véase, por ejemplo, PREDES, 2006). Se muestra una preferencia por el trabajo independiente, que permite reafirmar valores sobre los cuales las personas desarrollan su identidad, principalmente la idea de independencia (asociada al orgullo), las relaciones de orden social entre los pares (estatus) y rechazar aquellas asociadas a la vejez. En el caso de las mujeres, ello permite combinar también la generación de ingresos con las responsabilidades y necesidades de cuidado al interior del hogar:

“Acá nosotros, todo el día, de acá para allá. Todo el día. Y en un negocito no, porque va a estar en la casa, como más relajado. No vas a tener un jefe que te ande pensando si haces bien el trabajo o no. Va a ser como más relajado, porque va a ser en tu casa. Voy a estar en mi casa" (Mujer 6, densidad de cotización alta). 
Ahora bien, cabe notar que si bien la posibilidad de seguir trabajando constituye una fuente de esperanza en tanto alternativa de ingresos, la posibilidad de no poder hacerlo -por ejemplo, por enfermedad- rápidamente evoca sentimientos de angustia y desesperanza:

“¿Qué pasaría si usted no pudiera trabajar? Ese es mi problema, claro, pero tampoco quiero pensar en eso. No quiero pensar en el día de mañana que no puedo hacerlo. Yo siempre trato de pensar positivo que puedo hacerlo, que lo voy a poder hacer" (Hombre 10, densidad de cotización baja).

Una segunda estrategia es el ahorro. El ahorro con fines previsionales más directo es aquel que supone la adquisición de bienes de capital para iniciar una microempresa. La capacidad de utilizar esta estrategia tiene límites conocidos por las personas como el monto de las deudas y compromisos monetarios actuales, el nivel del ingreso actual y la composición y ciclo de vida familiar. Este último elemento es importante pues a mayor número de hijos en edad escolar, mayores son las necesidades de gasto presente:

“A veces pienso y digo: 'ya voy a empezar a ahorrar', pero como yo tengo una hija de 19 años, tengo un hijo de 13, no se puede (...). No puedo ahorrar porque piden plata. Hay que tenerles colación diaria a [su hijo], a [su hija] que necesita sacar fotocopias, que hay que pagar el internet, porque ella estudia con internet (...) entonces en este momento aunque yo quisiera no puedo" (Cecilia Valdés).

La familia es, en efecto, una institución central en cuanto a la provisión de protección social y generación de ingresos (González de la Rocha, 2006; CEPAL, 2005: cap. 4). En los relatos encontramos, sin embargo, que la evaluación de este mecanismo presenta altos grados de tensión y no se manifiesta de manera evidente como alternativa viable. Debido a cambios culturales (transformación de los patrones de sociabilidad y autoridad al interior de la familia, procesos de individualización, imágenes de la vejez, entre otros) (véanse también Kaztman y Filgueira, 1999: 11-12; CEPAL, 2005: cap. 4) se genera una situación en la cual la familia es vista como una protección de última instancia y no necesariamente como una alternativa determinante de la experiencia previsional. Por otro lado, existen también limitaciones materiales a la "utilización" de este mecanismo (se entiende que la situación económica del resto de la familia no es mejor que la propia).

Llama la atención la poca mención de los beneficios estatales y su incorporación únicamente como opciones residuales, esto es, cuando las anteriores no pueden realizarse. Por ejemplo, respecto de la pensión básica se menciona su bajo monto como un hecho que hace que esta sea vista sólo como un complemento de otras estrategias que pueden ser más efectivas, y no como una solución en sí misma, aun cuando es particularmente valorada por las mujeres pues permite un ingreso independiente del marido. La caridad, por ultimo, es una opción visualizada únicamente por aquellos cuyas perspectivas futuras son más negativas. 


\subsection{Re-encuadre 2: Nuevos tipos de gestión previsional}

\subsubsection{Gestión complementaria}

Las personas perciben un alto grado de complementariedad cruzada entre los distintos mecanismos que perciben como susceptibles de proveer ingresos para la vejez. Denominamos complementaria al tipo de gestión previsional en que las personas buscan mejorar su pensión de AFP desarrollando estrategias adicionales. La pensión de AFP constituye un flujo de recursos que, aun cuando no sea suficiente por sí mismo, es considerado relativamente seguro en cuanto a su periodicidad, y en ese sentido forma parte integrante de las estrategias más amplias para generar ingresos para la vejez. Esta es utilizada por personas que perciben una situación relativamente mejor en términos de su fondo de pensiones, por lo que la gestión de estos otros mecanismos resulta un complemento:

"A lo mejor la misma jubilación que me van a dar, jubilación de invalidez, podría armar un kiosquito y vivir de esa jubilación que tengo ahí y de mi kiosco que pueda ser parte de mi trabajo" (Hombre 3, densidad de cotización alta).

\subsubsection{Gestión sustitutiva}

A diferencia de lo que ocurre con la gestión complementaria, el fondo de pensiones constituye un referente negativo en el sentido de que obliga a que las personas pongan el acento en la gestión de otras estrategias con el objetivo de suplir la incapacidad de gestionar la AFP. De este modo, la diferencia en el desarrollo de la gestión complementaria y la gestión sustitutiva se encuentra fuertemente determinada por los condicionantes materiales y subjetivos, que se manifiestan en un mayor o menor éxito en la gestión referida al sistema de pensiones:

"A ver, lo que yo estoy pensando que con la jubilación que voy a sacar va a ser muy poca. Entonces estoy tratando de... Voy a tratar de juntar plata por otro lado y hacer inversiones. No sé, juntar plata, comprarme unas camionetas, hacer otras cosas, porque la jubilación la veo muy poca. Entonces tengo que tener otra entrada" (Hombre 14, densidad de cotización baja).

Mientras mayor es el grado de necesidad que anticipan estas personas, más disminuye su capacidad de agencia y de combinar nuevos mecanismos. Las alternativas se reducen y se ven en la obligación de utilizar mecanismos que no constituyen su primera opción. Esta situación es particularmente evidente en relación a la utilización de una pensión estatal o de la familia como forma de generar ingresos. Así, por ejemplo, las personas que mencionan no desear recibir apoyo de sus hijos contemplan como plausible una situación en que ésta sea la única alternativa que les quede. Uno de los elementos que producen una valoración negativa de la familia es la dependencia que genera, por contraste con las opciones que ofrece el trabajo independiente:

"Yo me veo viviendo con mi hija, porque ella me lo ha ofrecido. Ahora, también pienso que no quiero ser molestia para nadie (...). Lo ideal sería que toda nuestra generación 
estuviéramos juntos para compartir las mismas cosas y que no sean cargas de los hijos. O sea, para mí el tema es no ser carga para mis hijos, y es una de las cosas que me deprime y lamentablemente va a ser así" (Mujer 5, densidad de cotización alta).

\subsubsection{Gestiones negativas}

Finalmente hemos agregado bajo la noción de gestiones negativas aquellas que se definen no por la realización de un curso de acción o la toma de una cierta decisión con respecto a la previsión de la vejez, sino que denotan un "no hacer", un "omitir", o un hacer en direcciones que impactan de manera negativa y con consecuencias adversas en la generación de ingresos para la vejez. Una variante neutra o nula puede observarse en caso de acciones u omisiones que no contribuyen a mejorar la pensión futura, ni tampoco van directamente en su desmedro. Las causas son variadas: desidia o indiferencia, frustración, falta de activos (por ejemplo, tiempo o recursos), ignorancia, etc. Este tipo de gestión se caracteriza por la existencia de algún tipo de reflexión sobre la situación previsional, pero que no decanta en acciones concretas. El individuo es consciente de que puede realizarlas, pero no lo hace. Es común observar este tipo de gestión en personas con una vinculación inestable con el mercado del trabajo y con concepciones erróneas sobre el funcionamiento del sistema de pensiones.

Adicionalmente puede observarse una variante contraria correspondiente al rechazo por parte de la persona de realizar cualquier gestión tendiente a mejorar su situación previsional, sumado a una tendencia a tomar decisiones que empeoran su situación previsional. Entre estas últimas, por ejemplo, se encuentra el cotizar por el mínimo cuando se tienen empleos dependientes, de modo de utilizar al máximo posible los ingresos presentes para el consumo actual, lo que afecta la cantidad acumulada en el fondo de pensiones. En este tipo de gestión predominan la desconfianza con el sistema actual o una nula reflexión sobre el futuro por parte del agente, concentrándose las personas en dedicar todos sus recursos al consumo actual:

“Por ejemplo, a mí me están pagando doscientas lucas, pero me están pagando por ¿cómo se llama?, por el mínimo. El contrato es por el mínimo y uno dice: 'ah, es mejor porque uno saca más plata'" (Hombre 14, densidad de cotización baja).

\section{CONCLUSIONES}

Este artículo ha ofrecido una alternativa al estudio de las decisiones previsionales basado en una teoría sociológica de la acción. Se provee una interpretación dinámica de las posibilidades de agencia y las determinaciones estructurales que recaen sobre dichas posibilidades, en escenarios sociales altamente complejos y novedosos como el que presenta el sistema de pensiones chileno. Este, se argumentó, no constituye un entorno social cotidiano y conocido para los actores sociales. Por el contrario, tanto el objeto mismo de procuración -la pensión- como las lógicas de acción que el sistema promueve -la previsión del futuroy los comportamientos institucionales adecuados -racionalidad instrumental- deben ser construidos mediante complejos procesos sociales y culturales. Gracias a la acción de gatillantes como el ciclo de vida y los medios de comunicación, las personas pueden acceder 
a momentos de mayor reflexividad a partir de los cuales imaginar la manera de gestionar un nuevo ámbito de la vida e incorporarlo a sus rutinas cotidianas.

Este proceso puede calificarse como de encuadre, esto es, las personas deben ir gradualmente buscando información, recogiendo otros relatos y narrativas, atribuyendo sentidos, haciendo planes, tomando decisiones, etc., con el objeto de ser capaces de establecer los parámetros con los cuales gestionar su previsión. Se resaltó la importancia de determinantes materiales y subjetivos tanto en la capacidad de llevar a cabo el encuadre, como en su desbordamiento y la construcción de nuevos marcos. Así, aun cuando las personas muestren la capacidad creativa para generar marcos de calculabilidad en contextos altamente complejos y extraños como el sistema de pensiones chileno, estos son fácilmente desbordados y penetrados por otros ámbitos de la vida y sus lógicas de acción. Entre los procesos de desbordamiento cabe destacar los límites institucionales y su capacidad para alterar o constreñir decisiones, la dificultad para definir el objeto de procuración "pensión de vejez" en tanto bien de mercado en el contexto de diversas referencias sociales y culturales, y la omnipresencia de las necesidades presentes que impiden una adecuada planificación económica de la vejez.

Los condicionantes materiales, en este contexto, pueden ser analizados desde dos ángulos: por un lado, limitan en extremo la capacidad de las personas de involucrarse en tipos de gestión que impliquen acciones únicamente orientadas hacia el largo plazo; por el otro lado, las estrategias que los trabajadores/as de bajos ingresos utilizan actualmente para sobrellevar su vulnerabilidad económica constituyen la base sobre la cual se construyen nuevas formas de gestión.

El resultado de los procesos de reformateo que siguen al desbordamiento constituye una combinación compleja entre presente y futuro, donde por un lado el futuro es negado como posibilidad y su gestión subsumida como gestión del presente, y por otro las prácticas que sirven para la generación de ingresos en el presente son re-significadas en el contexto de la fusión del presente y el futuro. En términos de la gestión, esto conlleva un reformateo de las formas de gestión específicas al sistema de pensiones dentro del contexto más amplio del conjunto de formas de generación de ingresos actuales conocidos por las personas y sus familias. La innovación se cierra, de este modo, sobre la rutina y se establece en un nivel más restringido, acotada por las estructuras sociales. Si bien esto conlleva una pérdida de efectividad en el sentido estricto de los parámetros de éxito provistos por el sistema de pensiones, provee coherencia y eficacia probada en el contexto social específico en que se desenvuelven los trabajadores/as de bajos ingresos.

Para finalizar quisiéramos elaborar más en relación a un punto ilustrado por los procesos de desbordamiento que es imposible de captar en estudios cuantitativos, a saber, la innovación trunca y la economía política de los diseños institucionales. Como se mostró, lejos de únicamente aplicar marcos normativos internalizados o incluso recombinarlos inteligentemente, al enfrentarse ante la necesidad de encuadre y su desbordamiento, las personas son capaces de imaginar nuevas estrategias y marcos de referencia. En particular se hizo mención a la alternativa visualizada de retirar el fondo de forma anticipada de manera de utilizarlo como un capital para el inicio -o continuación- de un microemprendimiento. 
A través de esta alternativa, las personas logran no sólo encontrar una solución de carácter pragmático, sino también satisfactoria desde el punto de vista de sus propios parámetros, haciendo compatible la existencia de un mecanismo de ahorro forzoso con el deseo de liberarse del trabajo dependiente-cuando se está en esa condición-y de realizar su experiencia de empleo independiente, aumentando la autonomía y autosuficiencia y alejándose de las consideraciones negativas asociadas a la vejez.

Esta sin embargo constituye una alternativa de innovación trunca debido a la rigidez del marco institucional ofrecido por el sistema de pensiones. Así, la poca capacidad de los trabajadores/as de bajos ingresos de participar en los canales institucionalizados de seguridad social no proviene de su falta de repertorios de acción para gestionar el sistema de pensiones, tampoco absolutamente de sus determinantes materiales. En parte importante, esta se ve limitada por las dinámicas políticas que influyen en los diseños institucionales -que favorecen ciertas prácticas de generación de ingresos sobre otras- y la existencia de imposibilidades legales a la aplicación de prácticas innovadoras para satisfacer sus propias necesidades actuales y futuras ${ }^{21}$ :

“¿De qué manera se sentiría satisfecho con el sistema de AFP? Que se den un poco más para las personas, en el sentido de que le den la posibilidad... (...) si en un momento determinado no consiguen los fondos, que no ganen solamente ellos como empresa, sino que si yo estoy mal en mi fondo me den la posibilidad de yo poder hacerlo y poder hacer negocio con mi dinero ahora. Esto no se puede hacer, pero si yo pudiera pedir algo me gustaría que fuera de esa forma, que le dieran la posibilidad a las personas" (Hombre 1, densidad de cotización alta).

\section{BIBLIOGRAFÍA}

Arenas de Mesa, Alberto (2010): Historia de la Reforma Previsional Chilena: Una Experiencia Exitosa de Política Pública en Democracia, Oficina Internacional del Trabajo, Santiago.

(2006): "The Structural Pension Reform in Chile: Effects, Comparisons with Other Latin American Reforms, and Lessons", Oxford Review of Economic Policy, 22 (1), pp. 149-167.

Arrau, Patricio y Salvador Valdés (2002): "Para desconcentrar los fondos de pensiones y aumentar la competencia en su administración", Estudios Públicos, 85 (verano).

Arteaga A., Catalina y Sonia Pérez T. (2011): “Experiencias de vulnerabilidad: de las estrategias a las tácticas subjetivas", Universum (Ta/ca), 26 (2), pp. 67-81.

Barr, Nicholas y Peter Diamond (2006): "The Economics of Pensions", Oxford Review of Economic Policy, 22 (1), pp. 15-39.

21 Compárense estas reflexiones con la noción polanyiana de "doble movimiento" y las dinámicas de desincrustación/re-incrustación [disembedding-reembedding] gatilladas por al expansión de los mercados estudiadas por Polanyi (2001). Véanse también los trabajos sobre cambio institucional que ponen énfasis en la importancia de la interpretación de las reglas y la capacidad de los actores sociales de elaborar prácticas novedosas, así como también la relevancia de los recursos de poder al momento de imponer ciertas definiciones sobre otras (Streeck y Thelen, 2005). 
Barros, Macarena (2012): "Prácticas financieras en torno al uso del crédito en la industria del retail de Santiago", en José Ossandón (ed.): Destapando la caja negra/ Sociologías de los créditos de consumo en Chile, Instituto de Investigación en Ciencias Sociales (ICSO), Universidad Diego Portales, Santiago, pp. 113-132.

Beckert, Jens (2003): "Economic Sociology and Embeddedness: How Shall We Conceptualize Economic Action?", Journal of Economic Issues, 37 (3), pp. 769-787.

Berstein, Solange y Carolina Cabrita (2006): Los determinantes de la elección de AFP en Chile: nueva evidencia a partir de datos individuales, Serie Documentos de Trabajo, Superintendencia de AFP (SAFP), Santiago.

Berstein, Solange, Guillermo Larraín y Francisco Pino (2005): Cobertura, densidad y pensiones en Chile: proyecciones a 20 años plazo, Serie Documentos de Trabajo, Superintendencia de AFP (SAFP), 12, Santiago.

Berstein, Solange y José Luis Ruiz (2005): Sensibilidad de la demanda con consumidores desinformados: el caso de las AFP en Chile, Serie Documentos de Trabajo, Superintendencia de AFP (SAFP), Santiago.

Bertranou, Fabio M. (2007): Economía Informal, Trabajadores independientes y Cobertura de la Seguridad Social en Argentina, Chile y Uruguay, Oficina International del Trabajo, Santiago.

Bertranou, Fabio M. y Pablo Casalí (eds.) (2007): Los trabajadores independientes y la seguridad social, Ministerio de Trabajo, Empleo y Seguridad Social/Oficina de la OIT, Buenos Aires, en http:// www.oit.org.ar/portal/index.php?option=com_content\&view=article\&id=254:Ios-trabajadoresindependientes-y-la-seguridad-social\&catid=52:publicaciones-argentina (Accedido el 7 de septiembre de 2012).

Bourdieu, Pierre (2001): Las estructuras sociales de la economía, Manantial, Buenos Aires.

Çalışkan, Koray, y Michel Callon (2010): "Economization, part 2: a research programme for the study of markets", Economy and Society, 39 (1), p. 1.

Callon, Michel (1998a): "An essay on framing and overflowing: economic externalities revisited by sociology", en Michel Callon (ed.): Laws of the Markets, Wiley-Blackwell, Oxford, pp. 244-269.

(1998b): "Introduction: The embeddedness of economic markets in economics", en Michel Callon (ed.): Laws of the Markets, Wiley-Blackwell, Oxford, pp. 1-57.

Callon, Michel y Fabian Muniesa (2005): "Economic Markets as Calculative Collective Devices", Organization Studies, 26 (8), pp. 1229-1250.

Camerer, Colin F. y George Loewenstein (2004): “Behavioral Economics: Past, Present, Future”, en Colin F. Camerer, George Loewenstein y Matthew Rabin (eds.): Advances in Behavioral Economics, Princeton University Press, Princeton, NJ, pp. 3-51.

CENDA (2005): Chile: Proyección Previsional de la Población Afiliada y Cotizante a las AFP, Centro de Estudios Nacionales de Desarrollo Alternativo (CENDA)/Instituto de Normalización Previsional (INP), Santiago.

CEPAL (2005): Panorama social de América Latina 2004, Comisión Económica para América Latina y el Caribe (CEPAL)-Naciones Unidas, Santiago, en http://www.eclac.cl/cgibin/getProd.asp?xml=/ publicaciones/xml/6/20386/P20386.xml\&xsl=/dds/tpl/p9f.xsl (Accedido el 7 de septiembre de 2012). 
Chan, Sewin y Ann Huff Stevens (2003): What You Don't Know Can't Help You: Pension Knowledge and Retirement Decision Making, Working Paper, National Bureau of Economic Research (NBER), en http://ideas.repec.org/p/nbr/nberwo/10185.html (Accedido el 15 de marzo de 2012).

Corbo, Vittorio y Klaus Schmidt-Hebbel (2003): "Efectos Macroeconómicos de la Reforma de Pensiones en Chile", Conferencia "Resultados y Retos de las Reformas de Pensiones", Cancún (México), 15-16 de mayo.

Cox, Alejandra (2000): "El futuro de las pensiones en Chile: Diferencias según sexo", Estudios Públicos, 79.

Cronqvist, Henrik y Richard H. Thaler (2004): “Design Choices in Privatized Social-Security Systems: Learning from the Swedish Experience", American Economic Review, 94 (2), pp. 424-428.

Dalton, Benjamin (2004): "Creativity, Habit, and the Social Products of Creative Action: Revising Joas, Incorporating Bourdieu", Sociological Theory, 22 (4), pp. 603-622.

Dequech, David (2003): "Cognitive and Cultural Embeddedness: Combining Institutional Economics and Economic Sociology", Journal of Economic Issues, 37 (2), pp. 461-470.

DiMaggio, Paul (1997): "Culture and Cognition", Annual Review of Sociology, 23 (1), pp. 263-287.

Goffman, Erving (1986): Frame Analysis: An Essay on the Organization of Experience, Northeastern University Press, New York.

González de la Rocha, Mercedes (2006): Procesos domésticos y vulnerabilidad, perspectivas antropológicas de los hogares con oportunidades, Centro de Investigaciones y Estudios Superiores en Antropología Social (CIESAS), México, D.F.

Granovetter, Mark (1985): "Economic Action and Social Structure: The Problem of Embeddedness", American Journal of Sociology, 91 (3), pp. 481-510.

Hagestad, Gunhild y Dale Dannefer (2001): “Concepts and theories of aging: Beyond microfication in social science approaches", en Robert H. Binstock y Linda K. George (eds.): Handbook of Aging and the Social Sciences, Fifth Edition, Academic Press.

Huanchuan, Sandra y José Miguel Guzmán (2006): “Seguridad Económica y Pobreza en la Vejez: Tensiones, Expresiones y Desafíos para Políticas", Notas de Población, 33 (83), pp. 99-125.

Joas, Hans y Jens Beckert (2001): "Action Theory", en Jonathan H. Turner (ed.): Handbook of Sociological Theory, Kluwer Academic/Plenum Publishers, New York, pp. 269-285.

Kaztman, Rubén y Carlos Filgueira (1999): Marco conceptual sobre activos, vulnerabilidad y estructura de oportunidades, CEPAL, Montevideo.

Kaztman, Rubén y Guillermo Wormald (eds.) (2002): Trabajo y Ciudadanía: Los Cambiantes Rostros de la Integración y Exclusión Social en Cuatro Áreas Metropolitanas de América Latina, Fernando Errandonea, México, D.F.

Loewenstein, George (1999): Is more choice always better, National Academy of Social Insurance, Social Security Brief.

Madariaga, Aldo y Nicolás Pérez (2009): “Nuevas aproximaciones para el análisis de sistemas de protección social: La noción de desempeño institucional y su aplicación al sistema de pensiones chileno", Revista Mad, 20, pp. 1-41.

Mesa-Lago, Carmelo (2008): “Protección social en Chile: Reformas para mejorar la equidad”, Revista Internacional del Trabajo, 127 (4), pp. 421-446.

North, Douglass C. (2006): Instituciones, cambio institucional y desempeño económico, Fondo de Cultura Económica, México D.F. 
Osorio, Paulina (2007): “Construcción Social de la Vejez y Expectativas ante la Jubilación en Mujeres Chilenas", Universum (Ta/ca), 22 (2), pp. 194-212.

Ossandón, José (2009): "The Enactment of Social Health Insurance", PhD Thesis, Goldsmiths, University of London.

Ossandón, José y Sebastián Ureta (2012): "Taming uncivilized markets", artículo presentado en la conferencia anual de EGOS, Helsinki.

PNUD (2009): Desarrollo Humano en Chile: La manera de hacer las cosas, Programa de las Naciones Unidas para el Desarrollo (PNUD), Santiago.

Polanyi, Karl (2001): The Great Transformation, Segunda edición, Beacon Press, Boston, MA.

PREDES (2006): Estudio sobre las trayectorias laborales en las familias Puente, Fondo de Solidaridad e Inversión Social (FOSIS), Santiago, en http://www.chilesolidario.gov.cl/administrador/ arc_doc/211384877493eefc2223e2.pdf (Accedido el 15 de marzo de 2011).

Rodríguez, Federico y Cecilia Rossel (2009): Panorama de la vejez en Uruguay, United Nations Population Fund (UNFPA), Montevideo.

Ruiz-Tagle, Jaime y Pablo Tapia (2011): "Chile: Pensión anticipada, impaciencia y aversión al riesgo", Revista CEPAL, 105, pp. 113-132.

Schatzki, Theodore R. (1988): "The Nature of Social Reality", Philosophy and Phenomenological Research, 49 (2), pp. 239-260.

Streeck, Wolfgang y Kathleen Thelen (2005): "Introduction: Institutional Change in Advanced Political Economies", en Wolfgang Streeck y Kathleen Thelen (eds.): Beyond Continuity: Institutional Change in Advanced Political Economies, Oxford University Press, New York, pp. 1-39.

Subsecretaría de Previsión Social (2008): Multifondos y Conocimiento Financiero, Santiago

Sunden, Annika (2005): "How much do people need to know about their pensions and what do they know?", en Robert Holzmann y Edward Palmer (eds.): Pension Reform through NDCs: Issues and Prospects for Non-Financial Defined Contribution Schemes, World Bank, Washington D.C.

Thévenot, Laurent (2002): “Which Road To Follow? The Moral Complexity Of An 'Equipped' Humanity", en John Law y Annemarie Mol (eds.): Complexities: social studies of knowledge practices, Duke University Press, pp. 53-87.

Tokman, Víctor E. (2007): "Informalidad, inseguridad y cohesión social en América Latina", Serie Políticas Sociales, CEPAL, 130.

Uthoff, Andras (2001): "La reforma del sistema de pensiones en Chile. Desafíos pendientes", Serie Financiamiento del Desarrollo, CEPAL, 112.

Valdés, Salvador (2005): "Para aumentar la competencia entre las AFP", Estudios Públicos, 98 (otoño).

Villarreal, Magdalena (2011): "Cálculos financieros y fronteras sociales en una economía de deuda y morralla", Civitas-Revista de Ciências Sociais, 10 (3), pp. 392-409.

Zukin, Sharon y Paul DiMaggio (1990): "Introduction", en Structures of Capital: The Social Organization of the Economy, Cambridge University Press, New York, pp. 1-37. 